\title{
Heart transplantation and arterial elasticity
}

This article was published in the following Dove Press journal:

Transplant Research and Risk Management

23 December 2013

Number of times this article has been viewed

\section{Monica Colvin-Adams' \\ Nonyelum Harcourt ${ }^{1}$ \\ Robert LeDuc ${ }^{2}$ \\ Ganesh Raveendran' \\ Yassir Sonbol ${ }^{3}$ \\ Robert Wilson' \\ Daniel Duprez'}

'Cardiovascular Division, University of Minnesota, Minneapolis, MN, USA; ${ }^{2}$ Division of Biostatistics University of Minnesota, Minneapolis, MN, USA; ${ }^{3}$ Cardiovascular Division, St Luke's Hospital System, Sugar Land, TX, USA

Correspondence: Monica Colvin-Adams University of Minnesota, 420 Delaware Street SE, MMC 508, Minneapolis, MN 55455, USA

Email mcolvin@umn.edu
Objective: Arterial elasticity is a functional biomarker that has predictive value for cardiovascular morbidity and mortality in nontransplant populations. There is little information regarding arterial elasticity in heart transplant recipients. This study aimed to characterize small (SAE) and large (LAE) artery elasticity in heart transplant recipients in comparison with an asymptomatic population free of overt cardiovascular disease. A second goal was to identify demographic and clinical factors associated with arterial elasticity in this unique population.

Methods: Arterial pulse waveform was registered noninvasively at the radial artery in 71 heart transplant recipients between 2008 and 2010. SAEs and LAEs were derived from diastolic pulse contour analysis. Comparisons were made to a healthy cohort of 1,808 participants selected from our prevention clinic database. Multiple regression analyses were performed to evaluate associations between risk factors and SAE and LAE within the heart transplant recipients.

Results: LAE and SAE were significantly lower in heart transplant recipients than in the normal cohort $(P<0.01$ and $P<0.0001$, respectively). Female sex and history of ischemic cardiomyopathy were significantly associated with reduced LAE and SAE. Older age and the presence of moderate cardiac allograft vasculopathy were also significantly associated with reduced SAE. Transplant duration was associated with increased SAE.

Conclusion: Heart transplants are associated with peripheral endothelial dysfunction and arterial stiffness, as demonstrated by a significant reduction in SAE and LAE when compared with a healthy population. Furthermore, cardiac allograft vasculopathy is associated with a significant reduction in SAE, suggesting a potential use in screening heart transplant recipients at risk for developing this complication.

Keywords: heart transplant, endothelial function, arterial elasticity, cardiac allograft vasculopathy

\section{Introduction}

Heart transplantation has emerged as the definitive cure for end-stage heart failure. Short-term outcomes after heart transplant have improved substantially, but longterm outcomes remain poor because of malignancy, graft failure, and cardiac allograft vasculopathy (CAV), a condition that appears to be preceded by endothelial dysfunction. ${ }^{1,2}$ In the heart transplant recipient, subclinical coronary endothelial injury occurs early via a variety of mechanisms, such as donor injury and immune activation, and may be the precipitating event in CAV. These injuries promote a state of inflammation characterized by upregulation of inflammatory cytokines and growth hormones. ${ }^{3}$ As a result, abnormalities in vasomotor tone, as demonstrated by abnormal coronary responses to acetylcholine and abnormal brachial artery dilatation, have been 
demonstrated in asymptomatic heart transplant recipients and precede the development of CAV. ${ }^{4,5}$ The ability to identify abnormal vascular function noninvasively and before the development of CAV could be useful in identifying heart transplant recipients at greater risk for CAV.

Evaluation of arterial elasticity has the potential to provide important insight into the early functional changes that precede intimal thickening and the subsequent development of CAV. In the general population, small (SAE) and large (LAE) artery elasticity measured via the radial artery have been demonstrated to be prognostic. LAE, a marker of vascular stiffness that implies structural damage to the conduit arteries, is associated with cardiovascular risk. ${ }^{6,7} \mathrm{SAE}$, derived from diastolic radial pulse contour analysis, more closely correlates with endothelial (dys)function, as measured from reflected waves from the resistive vessels, and implies a functional change in vascular function. ${ }^{8,9}$

Noninvasively measured arterial elasticity may be useful in evaluating risk in heart transplant recipients. The goal of this preliminary study is to characterize SAE and LAE in heart transplant recipients by comparison with asymptomatic individuals free of overt cardiovascular disease and by identification of demographic and clinical factors associated with arterial elasticity in this unique population.

\section{Methods Study design}

The study protocol and informed consent procedures were approved by the University of Minnesota Human Subjects Review Committee. Investigations were in accordance with the Declaration of Helsinki. We conducted cross-sectional analyses to both test for differences in SAE and LAE between heart transplant recipients and normal controls and evaluate the associations between arterial elasticity and relevant demographic and clinical variables among heart transplant recipients. Data for heart transplant recipients were collected as part of a larger, ongoing, cross-sectional study to evaluate markers of endothelial function and their associations with the presence and severity of CAV. Control participants were selected from our existing prevention center database.

\section{Participants}

Heart transplant recipients undergoing routine annual clinical evaluations at the University of Minnesota Medical Center were invited to participate in the study. Patients were eligible if they were aged 18 years or older and had received their transplant at least 12 months ago. Patients were excluded if they had more than a single heart transplant; received multiple organs; had an active infection; were experiencing acute rejection (grade $3 \mathrm{a}$ or greater); or had stage 4 chronic kidney disease, defined as a glomerular filtration rate lower than $30 \mathrm{~mL} /$ minute per $1.73 \mathrm{~m}^{2}$, or acute renal failure. Sixtythree heart transplant recipients were enrolled.

Control subjects $(n=1,808)$ for these analyses were retrospectively selected from a database of asymptomatic patients who had undergone a cardiovascular screening (which included measurement of SAE and LAE) at the University of Minnesota Rasmussen Center for Cardiovascular Disease Prevention.

\section{Data collection}

Data for control group participants (age, sex, SAE, and LAE) were abstracted from the existing patient database at the Rasmussen Center. Heart transplant recipients underwent a clinical evaluation at study entry and completed a medical and demographic questionnaire to obtain information on history of tobacco use, diabetes, hypertension, and current medical therapy. This history was supplemented and confirmed by data collected from our center's clinical transplant database.

Participants in the heart transplant group were also assessed for CAV with coronary angiograms, read by two interventional cardiologists. The presence of CAV was defined as a stenosis of $25 \%$ or greater in an epicardial vessel on angiogram. The severity of CAV was assessed and scored on the basis of the following system: grade $0,0 \%$ stenosis; grade $1,25 \%$ stenosis or less; grade $2,26 \%-50 \%$ stenosis; grade 3, 51\%-75\% stenosis; and grade 4 , more than $75 \%$ stenosis. Moderate CAV was defined as grade $3 \mathrm{CAV}$ or greater.

\section{Measurement of arterial elasticity}

For determination of artery elasticity, radial artery pulse waveforms were acquired from all participants (control subjects and heart transplant subjects), using the CVProfilor (Hypertension Diagnostics, Inc, Eagan, MN, USA), which performs radial artery pulse wave analysis. The radial artery wave form was obtained using a sensor positioned over the artery and calibrated using an oscillometric method with a cuff on the opposite arm and a calibration system internal to the device. The device uses a previously described algorithm that is applied to define a third-order equation that replicates the diastolic decay and waveform. ${ }^{9} \mathrm{C} 1$ or capacitive compliance (LAE) and C2 or oscillatory compliance (SAE) are calculated from the radial artery pulse waveforms, using a modified Windkessel formula. This methodology, which has previously 
been described, provides a convenient way to assess both large conduit artery and small, resistance circulatory function. ${ }^{10,11}$ Tracings were reviewed for accuracy of measurement and sensitivity of capturing the waveform. Three measurements were obtained from each subject. The mean SAE and LAE values for each subject were used in the analysis.

\section{Statistical analysis}

Continuous measurements were summarized using the mean, standard deviation, median, and range. Counts and percentages were calculated for categorical variables. A $P$-value of $<0.05$ was considered to be statistically significant. Linear regression was used to compare SAE and LAE between heart transplant recipients and normal controls, both univariately and adjusting for age and sex. Linear regression limited to heart transplant recipients was also used to identify associations between SAE or LAE and the following variables: age, sex, presence of CAV, total cholesterol, high-density lipoprotein and low-density lipoprotein cholesterol, triglycerides, triglyceride/high-density lipoprotein ratio, systolic and diastolic blood pressure, transplant duration, history of ischemic cardiomyopathy (as reason for transplant), history of rejection, history of CMV infection, and immunosuppressant therapy (calcineurin inhibitor, mycophenolate mofetil, sirolimus). Two models were fit for each outcome. The first model used a binary covariate for the presence of CAV (grade 2 or above), and the second model used a binary covariate for the presence of moderate CAV (grade 3 or above).

\section{Results \\ Participant characteristics}

Baseline characteristics are reported in Table 1. Most (81\%) participants were men. The mean age was $58 \pm 12$ years, and the mean duration of transplant was $5.8 \pm 5.6$ years. Forty-eight percent of patients were transplanted for ischemic cardiomyopathy. Fifty-one percent of heart transplant recipients had CAV, and $23 \%$ had moderate CAV. The mean low-density lipoprotein level was $85 \mathrm{mg} / \mathrm{dL} ; 86 \%$ of patients were receiving statin therapy. In our sample of heart transplant recipients, $83 \%$ were taking a calcineurin inhibitor, either tacrolimus or cyclosporine. Seventy-three percent were taking mycophenolate mofetil, $29 \%$ sirolimus, and 3\% prednisone, and less than $2 \%$ were taking azathioprine.

\section{Association of heart transplantation with SAE and LAE}

In heart transplant recipients, the mean LAE was $14.9 \pm 5.1 \mathrm{~mL} / \mathrm{mmHg} \times 10$, and the mean $\mathrm{SAE}$ was
Table I Characteristics of heart transplant recipients, $n=63$

\begin{tabular}{lll}
\hline Characteristics & $\begin{array}{l}\text { Mean } \\
\text { or percentage }\end{array}$ & SD \\
\hline Age, years & 58.0 & 12.0 \\
Sex, \% male & 81.0 & - \\
Duration of transplant, years & 5.8 & 5.6 \\
Ischemic etiology, \% & 48.0 & \\
CAV present, \% & 51.0 & - \\
\% moderate cardiac allograft & 23.0 & - \\
vasculopathy, >grade 2 & & \\
Large artery elasticity, $\mathrm{mL} / \mathrm{mmHg} \times 10$ & 14.9 & 5.1 \\
Small artery elasticity, $\mathrm{mL} / \mathrm{mmHg} \times 100$ & 4.5 & 2.1 \\
Low-density lipoprotein, $\mathrm{mg} / \mathrm{dL}$ & 85.0 & 30.0 \\
Antihypertensive therapy, \% & 65.0 & \\
Statins, \% & 86.0 & - \\
Calcineurin inhibitors, \% & 83.0 & - \\
Mycophenolate mofetil, \% & 73.0 & - \\
Sirolimus, \% & 29.0 & - \\
\hline
\end{tabular}

Note: Antihypertensive therapy includes therapy with angiotensin-convertingenzyme inhibitors, angiotensin II receptor blockers, beta-blockers, or calcium channel blockers.

Abbreviations: SD, standard deviation; CAV, cardiac allograft vasculopathy.

$4.5 \pm 2.1 \mathrm{~mL} / \mathrm{mmHg} \times 100$. In the control group, the mean LAE was $16.6 \pm 5.58 \mathrm{~mL} / \mathrm{mmHg} \times 10$, and the mean SAE was $6.5 \pm 3.17 \mathrm{~mL} / \mathrm{mmHg} \times 100$. In unadjusted analyses (Table 2), both LAE and SAE were significantly lower in heart transplant recipients than in control subjects $(P<0.02$ and $P<0.0001$, respectively). After adjustment for age and sex (Table 2), heart transplant continued to be significantly associated with reduced LAE and $\operatorname{SAE}(P<0.01$ and $P<0.0001$, respectively). CAV was found in $51 \%$ of the heart transplant recipients. Exclusion of these patients from the analysis did not alter the basic finding, and after adjustment for age and sex, LAE and SAE were still significantly reduced in heart transplant recipients $(\mathrm{n}=26)$ compared with the LAE and SAE values for control subjects $(P=0.04$ and $P=0.0006$, respectively).

\section{Association of CAV risk factors with SAE and LAE}

Results for the univariate analyses are shown in Table 3. Reduced LAE was significantly associated with female sex $(P=0.0006)$ and increased triglyceride levels $(P=0.04)$. Specifically, female sex was associated with a significant reduction in LAE of $5.4 \mathrm{~mL} / \mathrm{mmHg} \times 10$, and increasing triglyceride level was associated with reduction in LAE. Older age, history of ischemic cardiomyopathy as indication for heart transplant, and higher triglyceride levels were significantly associated with reduced SAE. Increase in age by 1 year resulted in a $0.06 \mathrm{~mL} / \mathrm{mmHg} \times 100$ reduction in $\mathrm{SAE}$ $(P=0.007)$, history of ischemic cardiomyopathy reduced 
Table 2 Comparison between heart transplant patients $(n=63)$ and controls $(n=1,808)$

\begin{tabular}{|c|c|c|c|}
\hline Comparison & Beta & $95 \% \mathrm{Cl}$ & $P$-value \\
\hline \multicolumn{4}{|l|}{ Unadjusted } \\
\hline $\mathrm{LAE}, \mathrm{mL} / \mathrm{mmHg} \times 10$ & -1.73 & $-3.12,-0.33$ & $<0.02$ \\
\hline $\mathrm{SAE}, \mathrm{mL} / \mathrm{mmHg} \times 100$ & -1.99 & $-2.79,-1.21$ & $<0.0001$ \\
\hline \multicolumn{4}{|l|}{ Adjusted } \\
\hline \multicolumn{4}{|l|}{ Transplant } \\
\hline $\mathrm{LAE}, \mathrm{mL} / \mathrm{mmHg} \times 10$ & -1.74 & $-2.97,-0.5$ I & $<0.01$ \\
\hline $\mathrm{SAE}, \mathrm{mL} / \mathrm{mmHg} \times 100$ & -1.73 & $-2.39,-1.07$ & $<0.0001$ \\
\hline \multicolumn{4}{|l|}{ Female } \\
\hline $\mathrm{LAE}, \mathrm{mL} / \mathrm{mmHg} \times 10$ & -3.93 & $-4.38,-3.45$ & $<0.000 \mathrm{I}$ \\
\hline $\mathrm{SAE}, \mathrm{mL} / \mathrm{mmHg} \times 100$ & -1.98 & $-2.22,-1.75$ & $<0.0001$ \\
\hline \multicolumn{4}{|l|}{ Age } \\
\hline $\mathrm{LAE}, \mathrm{mL} / \mathrm{mmHg} \times 10$ & -0.16 & $-0.17,-0.14$ & $<0.0001$ \\
\hline $\mathrm{SAE}, \mathrm{mL} / \mathrm{mmHg} \times 100$ & -0.12 & $-0.13,-0.11$ & $<0.0001$ \\
\hline
\end{tabular}

Abbreviations: $\mathrm{Cl}$, confidence interval; $\mathrm{LAE}$, large artery elasticity; SAE, small artery elasticity.

SAE by $1.15 \mathrm{~mL} / \mathrm{mmHg} \times 100(P=0.03)$, and high-density lipoprotein was associated with a $0.04 \mathrm{~mL} / \mathrm{mmHg} \times 100$ reduction in $\operatorname{SAE}(P=0.04)$.

Results for the stepwise multiple regression models are shown in Table 4. In the final models that adjust for selected risk factors for CAV, female sex retained its significant, independent association with reduced LAE $(\beta=-7.26$; $P<0.0001)$. In addition, history of ischemic cardiomyopathy was found to be associated with a $3.24 \mathrm{~mL} / \mathrm{mmHg} \times 10$ reduction in $\operatorname{LAE}(P=0.01)$. Older age and history of ischemic cardiomyopathy remained significantly associated with reduced SAE. In addition, female sex was associated with a $2.16 \mathrm{~mL} / \mathrm{mmHg} \times 100$ reduction in $\mathrm{SAE}(P<0.002)$, and the presence of moderate $\mathrm{CAV}$ was associated with a $1.51 \mathrm{~mL} / \mathrm{mmHg} \times 100$ reduction in $\operatorname{SAE}(P<0.02)$. Two other clinical variables, low-density lipoprotein levels and duration of heart transplant, were associated with increased SAE (0.02 and $0.14 \mathrm{~mL} / \mathrm{mmHg} \times 100$ increases in SAE, respectively). History of CMV infection, rejection, or current use of MMF, CNI, or sirolimus were associated with arterial elasticity.

\section{Discussion}

The results from our analyses indicate that heart transplantation is independently associated with reduced SAE and LAE when compared with healthy controls. There are multiple known contributors to abnormal vascular function after transplant, including T-cell and B-cell activation, donor injury, effects of immunosuppression, and the presence of more common risk factors such as hypertension and diabetes. The anatomical effects of the heart transplant surgery itself and resulting abnormal ventriculo-vascular coupling may also propagate vascular dysfunction. Our results suggest that these multiple transplant-related mechanisms, leading to alterations in vascular tone, ultimately may result in reduced SAE and LAE.

To generate hypotheses about the possible mechanisms of arterial stiffness in heart transplant recipients, and to preliminarily explore the potential of arterial elasticity measurements as functional biomarkers for CAV, we examined the associations among SAE/LAE, CAV, and several known risk factors of CAV. Patient age, sex, history of ischemic heart disease, duration of transplant, low-density lipoprotein levels, and presence of CAV were all significant correlates of artery elasticity in our sample.

Measurement of SAE by pulse contour analysis reflects the functional behavior of the small and resistance arteries, which is affected by alterations in the concentrations of endothelial-derived substances and structural changes. In our heart transplant sample, increasing age, female sex, history of ischemic cardiomyopathy, and presence of moderate CAV were independently associated with reduced SAE. In nontransplant populations, SAE is an independent risk marker for cardiovascular events, including myocardial infarction, coronary bypass surgery, coronary angioplasty, peripheral arterial disease, and cerebrovascular events, but the relationship between SAE and CAV has not been described. ${ }^{10,12-15}$ Coronary endothelial dysfunction precedes the development

Table 3 Significant univariate associations between large artery elasticity/small artery elasticity and selected covariates in heart transplant recipients

\begin{tabular}{|c|c|c|c|c|c|c|}
\hline \multirow[t]{2}{*}{ Variable, $n=56$} & \multicolumn{3}{|c|}{ Large artery elasticity $(\mathrm{mL} / \mathrm{mmHg} \times 10)$} & \multicolumn{3}{|c|}{ Small artery elasticity $(\mathrm{mL} / \mathrm{mmHg} \times 100)$} \\
\hline & Beta & $95 \% \mathrm{Cl}$ & $P$-value & Beta & $95 \% \mathrm{Cl}$ & $P$-value \\
\hline Age, years & -0.05 & {$[-0.16,0.05]$} & 0.34 & -0.06 & {$[-0.096,-0.016]$} & $0.007^{*}$ \\
\hline Female & -5.4 & {$[-8.39,-2.4 I]$} & $0.0006 *$ & -1.15 & {$[-2.43,0.12]$} & NS \\
\hline Ischemic & -0.82 & {$[-3.52,1.88]$} & NS & -1.15 & {$[-2.21,-0.09]$} & $0.03 *$ \\
\hline High-density lipoprotein & -0.03 & {$[-0.13,0.07]$} & NS & -0.04 & {$[-0.08,-0.002]$} & $0.04 *$ \\
\hline Triglycerides & -0.02 & {$[-0.035,-0.00 \mathrm{I}]$} & $0.04 *$ & -0.005 & {$[-0.01,0.002]$} & NS \\
\hline
\end{tabular}

Note: *Statistically significant $P$-values $<0.05$.

Abbreviations: $\mathrm{Cl}$, confidence interval; NS, not significant. 
Table 4 Stepwise selection multiple regression for large artery elasticity/small artery elasticity: significant determinants of arterial elasticity in heart transplant recipients

\begin{tabular}{|c|c|c|c|c|c|c|}
\hline \multirow[t]{2}{*}{ Variable, $n=56$} & \multicolumn{3}{|c|}{ Large artery elasticity $(\mathrm{mL} / \mathrm{mmHg} \times 10)$} & \multicolumn{3}{|c|}{ Small artery elasticity $(\mathrm{mL} / \mathrm{mmHg} \times 100)$} \\
\hline & Beta & $95 \% \mathrm{Cl}$ & $P$-value & Beta & $95 \% \mathrm{Cl}$ & $P$-value \\
\hline Age, years & & & & -0.07 & {$[-0.11,-0.028]$} & $<0.002$ \\
\hline Female & -7.26 & {$[-10.44,-4.08]$} & $<0.0001$ & -2.16 & {$[-3.43,-0.89]$} & $<0.002$ \\
\hline Transplant duration & & & & 0.14 & {$[0.05,0.23]$} & $<0.005$ \\
\hline $\begin{array}{l}\text { Moderate cardiac allograft } \\
\text { vasculopathy }\end{array}$ & & & & -1.51 & {$[-2.74,-0.28]$} & $<0.02$ \\
\hline Ischemic history & -3.24 & {$[-5.65,-0.82]$} & 0.01 & -1.42 & {$[-2.47,-0.37]$} & 0.01 \\
\hline Diastolic blood pressure & -0.13 & {$[-0.25,-0.002]$} & 0.05 & -0.04 & {$[-0.091,0.005]$} & 0.08 \\
\hline Low-density lipoprotein & & & & 0.02 & {$[0.001,0.033]$} & 0.04 \\
\hline
\end{tabular}

Note: Variables with missing estimates were not part of the final selected model.

Abbreviation: $\mathrm{Cl}$, confidence interval.

of CAV, and minimal lesions have been shown to cause coronary endothelial dysfunction. ${ }^{16}$ In our study, moderate CAV was significantly associated with reduced SAE. We unexpectedly found that increasing duration of transplant was associated with increased (improved) SAE (Figure 1). This could potentially be explained by time-related positive vascular remodeling, as the size of the vessel influences SAE, although we would have expected a similar association between transplant duration and LAE, which was not observed. An alternative explanation is the "healthy worker" effect; that is, heart transplant recipients who have survived longer may, in general, be healthier than nonsurvivors, who would not have been included in our analysis. Another hypothesis would be an improvement in ventriculo-arterial coupling late after heart transplant.

To a lesser degree, large artery stiffness is a predictor of cardiovascular events and is determined by age, sex, and blood pressure in the nontransplant population..$^{9,17-21}$ In our sample of heart transplant recipients, female sex and ischemic heart disease were significantly and independently associated with reduced LAE, but not CAV. This lack of association may be related to the unique pathophysiologic and anatomic characteristics of CAV, which differentiate it from atherosclerotic disease.

Peripheral endothelial function has been shown to improve after heart transplantation, but the degree of improvement may be influenced by the etiology of heart failure. ${ }^{22,23}$ In previous work, endothelial dysfunction measured by aortic augmentation index was associated with etiology of heart failure and improved after transplantation. ${ }^{24}$ Contrary to these findings, persistent peripheral endothelial dysfunction, evaluated by skin laser-Doppler perfusion, has been documented in patients up to 13 years after transplant. ${ }^{25}$ In a small study of 20 heart transplant recipients, brachial artery reactivity appeared to be normal in heart transplant recipients with antecedent nonischemic cardiomyopathy at an average of $33 \pm 8$ months after transplant but remained reduced in recipients with history of ischemic cardiomyopathy. ${ }^{22,26} \mathrm{We}$ found a similar association between prior ischemic cardiomyopathy and SAE, suggesting that antecedent coronary artery disease, with the attendant inflammatory milieu and vascular injury, plays a significant role in determining endothelial function after transplant, despite improvements in hemodynamics and neurohormonal regulation.

The development of management strategies for CAV is limited by a lack of sensitive, practical, and prognostic screening and diagnostic tests. The ability to assess changes in vascular environment before the development of CAV would greatly enhance our ability to prevent CAV while limiting the heart transplant recipient's exposure to repeated coronary angiograms. Because our analyses were crosssectional, we cannot draw conclusions about the predictive value of SAE and LAE. Nonetheless, our finding of an association between reduced SAE and the presence of moderate $\mathrm{CAV}$ is promising for future studies evaluating the role of

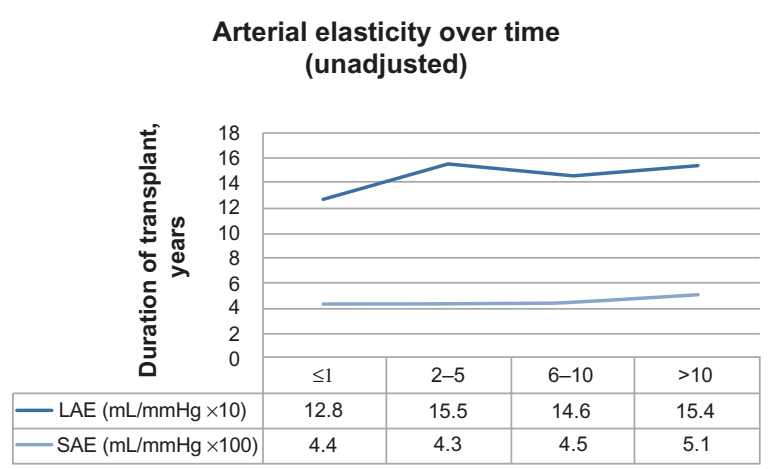

Figure I Change in arterial elasticity over time.

Abbreviations: LAE, large artery elasticity; SAE, small artery elasticity. 
SAE in predicting events and as a therapeutic target in heart transplant recipients.

\section{Limitations}

The use of angiogram instead of intravascular ultrasound could have led to an underestimation of the degree of CAV and, subsequently, misclassification. Coronary angiogram, however, represents the gold standard for the diagnosis of $\mathrm{CAV}$, and despite the increased sensitivity of intravascular ultrasound, coronary angiogram mirrors clinical practice.

The small sample size limited the ability to investigate more thoroughly the transplant-specific factors that might uniquely contribute to arterial elasticity. We acknowledge that a heart failure population may have provided a more suitable baseline control group; however, we believe the current comparison is valid in characterizing arterial elasticity in a quiescent, asymptomatic heart transplant population and provides useful information on this modality in the heart transplant recipient. In addition, the associations demonstrated were adjusted for etiology of heart failure, a potential determinant of endothelial function before transplant. Because the association of SAE with CAV was present after adjusting for etiology, we believe this analysis does account for factors that influence endothelial function that may have been present before transplant during heart failure. Finally, we acknowledge that causation cannot be concluded from a cross-sectional design, and longitudinal research is needed to determine the direction of the associations reported here. Nonetheless, this study does provide an important and novel snapshot of the peripheral vascular environment in heart transplant recipients and identifies several potential determinants of arterial stiffness after transplantation. Studies are in progress to evaluate the role of SAE as a predictor of CAV and related events.

\section{Conclusion}

In conclusion, our findings support the hypothesis that heart transplantation is independently associated with decreased endothelial function and increased arterial stiffness, as indicated by reduced SAE and LAE, respectively. There are some similarities in correlates of vascular stiffness between heart transplant recipients and nontransplanted patients (eg, age, female sex, and history of native CAD); however, the presence of moderate angiographic CAV was significantly and independently associated with reduced SAE. This finding suggests it may be possible to screen and identify patients at risk for CAV using a clinically applicable, noninvasive method. This needs to be confirmed through longitudinal study.

\section{Acknowledgments}

Special thanks to Jay Cohn, MD, who provided guidance regarding study design and interpretation of results, to Greg Grandits, $\mathrm{PhD}$, for preliminary analyses, to Eduardo Medina who helped initiate this study, and to Anne Marie Weber-Main, $\mathrm{PhD}$, who critically reviewed and edited article drafts.

\section{Disclosure}

Dr Colvin-Adams receives grant support through the National Institutes of Health K12 program and the American Heart Association. This research was partially funded by the National Institutes of Health. The authors report no other conflicts of interest in this work.

\section{References}

1. International Society of Heart and Lung Transplantation (ISHLT) Quarterly Data Report 2013.

2. Scientific Registry of Transplant Recipients (SRTR) Annual Data Report 2011. [webpage on the Internet]. Available from http://srtr.transplant. hrsa.gov/annual_reports/2011/. Accessed September 27, 2013.

3. Valantine HA. Cardiac allograft vasculopathy: central role of endothelial injury leading to transplant "atheroma". Transplantation. 2003;76(6): 891-899.

4. Fearon WF, Hirohata A, Nakamura M, et al. Discordant changes in epicardial and microvascular coronary physiology after cardiac transplantation: Physiologic Investigation for Transplant Arteriopathy II (PITA II) study. J Heart Lung Transplant. 2006;25(7):765-771 .

5. Davis SF, Yeung AC, Meredith IT, et al. Early endothelial dysfunction predicts the development of transplant coronary artery disease at 1 year posttransplant. Circulation. 1996;93(3):457-462.

6. Oliver JJ, Webb DJ. Noninvasive assessment of arterial stiffness and risk of atherosclerotic events. Arterioscler Thromb Vasc Biol. 2003;23(4): 554-566.

7. Simons PC, Algra A, Bots ML, Grobbee DE, van der Graaf Y. Common carotid intima-media thickness and arterial stiffness: indicators of cardiovascular risk in high-risk patients. The SMART Study (Second Manifestations of ARTerial disease). Circulation. 1999;100(9):951-957.

8. Bratteli CW, Cohn JN, Finkelstein SM, Morgan DJ, inventors; Hypertension Diagnostics, Inc, assignee. Apparatus and method for blood pressure pulse waveform contour analysis. United States Patent US6394958 B1. May 28, 2002.

9. Grey E, Bratteli C, Glasser SP, et al. Reduced small artery but not large artery elasticity is an independent risk marker for cardiovascular events. Am J Hypertens. 2003;16(4):265-269.

10. Duprez DA, Jacobs DR Jr, Lutsey PL, et al. Association of small artery elasticity with incident cardiovascular disease in older adults: the multiethnic study of atherosclerosis. Am J Epidemiol. 2011;174(5): 528-536.

11. Finkelstein SM, Collins VR, Cohn JN. Arterial vascular compliance response to vasodilators by Fourier and pulse contour analysis. Hypertension. 1988;12(4):380-387.

12. Duprez DA, Jacobs DR Jr, Lutsey PL, et al. Race/ethnic and sex differences in large and small artery elasticity - results of the multi-ethnic study of atherosclerosis (MESA). Ethn Dis. 2009;19(3):243-250.

13. Cohn JN, Duprez DA, Finkelstein SM. Comprehensive noninvasive arterial vascular evaluation. Future Cardiol. 2009;5(6):573-579.

14. Zimlichman R, Shargorodsky M, Boaz M, et al. Determination of arterial compliance using blood pressure waveform analysis with the CR-2000 system: reliability, repeatability, and establishment of normal values for healthy European population - the seven European sites study (SESS). Am J Hypertens. 2005;18(1):65-71. 
15. Duprez DA, Cohn JN. Arterial stiffness as a risk factor for coronary atherosclerosis. Curr Atheroscler Rep. 2007;9(2):139-144.

16. Fish RD, Nabel EG, Selwyn AP, et al. Responses of coronary arteries of cardiac transplant patients to acetylcholine. J Clin Invest. 1988;81(1): 21-31.

17. Kingwell BA, Waddell TK, Medley TL, Cameron JD, Dart AM. Large artery stiffness predicts ischemic threshold in patients with coronary artery disease. J Am Coll Cardiol. 2002;40(4):773-779.

18. Vaitkevicius PV, Fleg JL, Engel JH, et al. Effects of age and aerobic capacity on arterial stiffness in healthy adults. Circulation. 1993;88(4 Pt 1):1456-1462.

19. Cameron JD, Jennings GL, Dart AM. The relationship between arterial compliance, age, blood pressure and serum lipid levels. J Hypertens. 1995;13(12 Pt 2):1718-1723.

20. Gatzka CD, Cameron JD, Kingwell BA, Dart AM. Relation between coronary artery disease, aortic stiffness, and left ventricular structure in a population sample. Hypertension. 1998;32(3):575-578.

21. Benetos A, Waeber B, Izzo J, et al. Influence of age, risk factors, and cardiovascular and renal disease on arterial stiffness: clinical applications. Am J Hypertens. 2002;15(12):1101-1108.
22. Kubo SH, Rector TS, Bank AJ, et al. Effects of cardiac transplantation on endothelium-dependent dilation of the peripheral vasculature in congestive heart failure. Am J Cardiol. 1993;71(1):88-93.

23. Sinoway LI, Minotti JR, Davis D, et al. Delayed reversal of impaired vasodilation in congestive heart failure after heart transplantation. Am J Cardiol. 1988;61(13):1076-1079.

24. Pierce GL, Schofield RS, Nichols WW, Hill JA, Braith RW. Role of heart failure etiology on arterial wave reflection in heart transplant recipients: relation with C-reactive protein. J Hypertens. 2007;25(11): 2273-2279.

25. Holm T, Aukrust P, Andreassen AK, et al. Peripheral endothelial dysfunction in heart transplant recipients: possible role of proinflammatory cytokines. Clin Transplant. 2000;14(3):218-225.

26. Patel AR, Kuvin JT, Pandian NG, et al. Heart failure etiology affects peripheral vascular endothelial function after cardiac transplantation. J Am Coll Cardiol. 2001;37(1):195-200.

27. Cohn JN, Finkelstein S, McVeigh G, et al. Noninvasive pulse wave analysis for the early detection of vascular disease. Hypertension. 1995;26(3):503-508.
Transplant Research and Risk Management

\section{Publish your work in this journal}

Transplant Research and Risk Management is an international, peerreviewed open access journal focusing on all aspects of transplantation and risk management to achieve optimal outcomes in the recipient improving survival and quality of life. The journal welcomes submitted papers covering original research, basic science, clinical studies,

\section{Dovepress}

reviews \& evaluations, guidelines, expert opinion and commentary, case reports and extended reports. The manuscript management system is completely online and includes a very quick and fair peer-review system, which is all easy to use. Visit http://www.dovepress.com/ testimonials.php to read real quotes from published authors.

Submit your manuscript here: http://www.dovepress.com/transplant-research-and-risk-management-journal 